\title{
The Best Available Evidence: Assessing the Quality of Nursing Students' Bibliographies
}

\author{
David Brown \\ University of York, UK \\ Ted Hewitt \\ University of York, UK \\ Devi Nannen \\ University of York, UK \\ Jessica Powell \\ University of York, UK \\ Anita Savage Grainge \\ University of York, UK
}

\begin{abstract}
Librarians and academic staff suggest a relationship between the quality of references which students use in academic assignments and the marks received. This study tested that assertion by using a citation analysis methodology to assess the quality of bibliographies written by undergraduate nursing students at the University of York.
\end{abstract}

Bibliographies from sixty essays across three modules were analysed, noting the types and quantities of references used and whether references were sourced independently or included in the module's reading list. Each bibliography was given an overall quality rating: 'Poor', 'Average' or 'Good'. This rating was compared with the mark the student was awarded for the essay.

Results showed that, whilst students demonstrated the ability to locate items independently, the quality of those items was often poor. Generally, quality of selected sources and bibliographies improved as students progressed through the programme. There was an association between higher quality bibliographies and higher assignment marks.

The study concludes that critical thinking skills are vital for nursing students to develop academically, as these skills will be tested within a clinical environment once students have completed their degree. A benefit for students is the conclusion that using higher quality sources results in higher marks.

\section{Introduction}

This study aims to explore the type of evidence used in essay assignments by students on the BSc Nursing programme at the University of York, and to determine whether there is any relationship between the quality of references used and the student's final 
mark for the assignment. Anecdotal feedback from tutors on the BSc Nursing programme suggests that students often cite outdated, unreliable or otherwise inappropriate sources in their academic assignments. This was also a theme of a recent review of digital literacy provision conducted for the Health Sciences department by the University Library, in which teaching staff expressed concerns about students presenting limited and one-sided arguments within their essay submissions.

Students in the BSc Nursing programme receive digital literacy training embedded in specific modules, in each stage. In year 1 they are introduced to the importance of literature searching skills to professional practice, and given a basic grounding in principles of effective searching. This is expanded in year 2 to cover more advanced search techniques and additional evidence-based resources. In year 3 students receive support to carry out the literature review for their Service Improvement Project (an independent project akin to a dissertation). This support is delivered via face-toface workshops, supplemented with a range of self-paced online tutorials. Students are also welcome to book 1:1 appointments for additional guidance.

This study, a collaborative effort between library and academic staff, aims to provide more rigorous evidence about students' citation habits, which could better inform digital literacy provision across the programme. Citation analysis is used to determine exactly what types of citations students include in their written work, as well as the extent to which students discover those sources independently rather than using recommended reading items. Although the exercise did not originally intend to analyse the formatting or accuracy of references within each assignment, general trends on these points are also observed. Once a measure of quality had been ascertained for each assignment, this is compared against the mark awarded in order to note general trends and to determine whether high quality referencing could be viewed as a success factor for student work. For the purposes of this study, the term bibliography defines the list of references cited in the text of an assignment.

\section{Background}

This research identifies three key themes from the existing literature: how students generally engage with resources; how nursing students specifically engage with resources; and how citation analysis has been used as a research tool in previous studies. These themes were reviewed to inform the study.

\section{Student engagement with resources}

The literature presents a mixed picture with regard to the types of resources which students cite most frequently in their academic assignments. Mill (2008: 346), for example, finds that students tend to favour traditional academic resources such as books and journals over freely available online resources. This behaviour is also noted by Gannon-Leary et al. (2006: 257), who similarly find that books and journals are the forms of literature most cited by nursing students. Some studies, however, (e.g. Davis 2002: 56, Davis and Cohen 2001: 311) observe a decline in the use of traditional scholarly citations, with students instead favouring website sources. This dichotomy is perhaps not surprising given that many contemporary forms of research output are simply not viewed as academically rigorous (Gray et al. 2008); such a landscape surely makes it difficult for students to understand what is acceptable to cite for any given purpose. Even muddier is the assertion that only academic libraries provide students with authoritative evidence, despite free web tools now returning results which often match the academic library for quality (Georgas 2015: 147). 
Some studies also explore the quality of sources which students select, as well as type or format. Joo and Choi (2015: 278) investigate the criteria by which undergraduate students select sources to include in their assignments. They find that students most value ease of access to a source rather than its credibility and trustworthiness. Kim and Sin (2011: 184) also report that students most value accessibility as a selection tool. This suggests that, rather than looking for the most credible or authoritative sources, students will often demonstrate a pragmatic attitude to resource discovery and use those items which are most readily available. Furthermore, Rosenblatt (2010: 57) adds that, whilst students have little difficulty in finding resources and evaluating them against a set of given criteria, they struggle to integrate that source material effectively and critically to build an argument in their academic work. Rosenblatt (2010: 56) suggests that students are not necessarily influenced by library sessions delivered by the faculty's librarian providing instruction on how to locate, retrieve and analyse source material. Faculty staff's suggestions of core texts or reading material are perceived as the "gold standard"; however, students are still failing to incorporate source material successfully into their academic writing (Gimenez 2008). Once students understand the fundamental reasons for the use of source material, they must come to believe in the 'inherent goodness' or helpfulness of the different sources of material they will select for their assignments (Rosenblatt 2010: 50).

\section{Nursing student engagement with resources}

Much of the literature around students' information-seeking behaviour focuses on undergraduate students in a general sense. There is comparatively little which focuses specifically on the behaviour of nursing students as a distinct group. Within the nursing literature, information-seeking behaviour is most frequently investigated with regard to post-registration nurses, with much of those sources originating from a library and information science background. Of the literature around student nurses, there is a clear focus on their ability (or not) to search for material, but very little focus on how pre-registration nurses go about selecting resources.

Notable studies include Dee and Stanley (2005), who compare the searching habits of practicing nurses and student nurses. They find student nurses are more capable with using electronic databases and accessing a wide range of resources - highlighting an ability to find material - and are generally more confident than their post-registration counterparts. They note, however, that when it comes to selecting sources, nursing students exhibit the same tendency as other undergraduate students to favour accessibility over credibility. This could be because student nurses report finding it difficult to distinguish between good and bad quality information sources (Brown et al. 2010: 523), a worrying prospect given the focus within nursing education on evidencebased practice. It may be, however, that students need time across their degree to come to a reasoned understanding of the plurality of knowledge which allows them to embrace a wider range of source material (Belenky 1997, King and Kitchener 1994). As Eriksson and Mäkitalo (2013: 182) note of engineering students, in order to improve students' use of sources we must recognise the process by which students socialise to the disciplinary discourse.

Furthermore, Nayda and Rankin (2008: 30 ) report that nursing students do not see the value of information seeking to their lifelong learning. Students, rather, are very assignment-focused and are not applying their skills of literature searching within a professional context. This is despite the ability to 'practise in line with the best available evidence' being a core component of the Nursing and Midwifery Council's Code for Nurses and Midwives (Nursing and Midwifery Council 2015: 7). 
Within the nursing literature, the importance of critical thinking is highlighted for nurse education. Sullivan (2012), for example, outlines the link between critical thinking and nursing practice. In their scoping review of critical thinking in the nursing literature, Zuriguel-Pérez et al. (2014: 823) find that critical thinking is most often discussed amongst student nurses rather than other nurse practitioner groups. Profetto-McGrath (2003: 574), however, notes that nursing students are not engaging in critical thinking. In particular they observe that students do not seek truth in the literature; in other words, they accept what is presented to them without question. A more positive relationship to critical thinking is seen in Pitt et al. (2015: 128), who explore the relationship between critical thinking ability and academic performance for preregistration nurses. Their findings suggest that student nurses enter programmes with comparatively low critical thinking ability against other students, but reach a norm by the end of the programme. They further suggest that critical thinking ability be used as a selection tool during programme entry for pre-registration nurses.

The literature therefore presents a mixed picture of how nursing students engage with critical thinking in their academic practice. Whilst not all registered nurses will need to write academic papers, it will remain vital that they demonstrate the critical faculties developed through academic writing when gathering and considering evidence for a care intervention. Regardless of their field of practice, nurses must develop the ability to be critical and to build an argument, both of which are skills closely associated with academic writing. Nurse educators must therefore design academic work which develops students' ability to perform these functions in academic practice (Heller-Ross 2003: 133).

\section{Citation analysis as a research tool}

Citation analysis is a well-developed and well-recognised research methodology used by educators and academic librarians (Heller-Ross 2003: 120). Much of the literature which uses citation analysis as a research method is from academic librarians, who most often are interested in its potential to assist collection development and inform purchasing decisions, or to compare students' use of print and electronic resources (Gannon-Leary et al. 2006). There is also a significant body of this literature which uses citation analysis to measure the impact of library and literature searching instruction, seeking to identify whether student outcomes are improved as a result of that intervention. Such studies (e.g. Kohn and Gordon 2014, Middleton 2005, and Ursin, Lindsay and Johnson 2004) have attempted to measure the quality of students' citations in order to assess student learning. The purpose of these studies is varied, with some looking at specific student groups and others comparing students across different year groups and disciplines (e.g. Carlson 2006).

Relatively few studies use citation analysis as a tool for exploring resource use by student nurses specifically. Heller-Ross (2003), for example, compared the citations in the work of student nurses from four different classes, primarily to investigate the differences in citations between on- and off-campus students. Gannon-Leary et al. (2006) also explored citations used by student nurses, both to pick up the mixture of resources cited (the librarians' particular interest) and to identify the quality of selected resources (of interest to academics).

There are few examples of studies which link citation analysis specifically to student outcome and none which explore the interaction between the type and quality of selected citations and the students' academic results. This study aims to explore further the link between 'quality' of references and academic performance. 


\section{Methods}

For the citation analysis, a random sample of twenty essay submissions was selected for three different assignments, one from each year of the three-year BSc Nursing programme. The essays were provided by the department's Exams Office; all assignments had been submitted electronically through the University's Virtual Learning Environment, which ensures anonymity as part of the submission. Ethical approval to use students' work for the research was sought and granted.

The three modules selected were all examples of the BSc Nursing programme's Cooperative Learning Group (CLG) modules. The CLG model forms peer learning groups for students; students stay in these groups for the duration of the programme and follow a structured set of modules (six in total) which explore core themes in Nursing. This study chose three of these CLG modules, which explored themes around the Good Nurse, the Nurse-Patient Partnership and Ethical Principles in Nursing Practice (CLG modules 2, 4 and 5, respectively). Each of these module's assignments specifically required students to draw on academic literature in their responses, so were deemed suitable for the citation analysis exercise. The assignment guidelines for each module are provided in Appendix 1.

Each essay was analysed to identify a number of factors. The total number of references used in the submission was noted, as were the types of reference used. These were broken down into broad categories (italics show the names of the categories used):

- a book or chapter within a book;

- a journal article;

- a website or web page;

- a report, either in print or online;

- any other type of reference not included within the above categories;

- references which were indeterminate from the information provided.

Although there was potential for different interpretation of these categories, the same researcher carried out the analysis on all essay examples to ensure consistency. The analysis also identified the number of references which had been recommended on the relevant reading list. Each submission was compared against the reading list for the respective module, although of course resources might have been recommended in other modules.

Only the bibliography from each essay was analysed, not the full submission nor any in-text citations. Each manuscript was given a unique identifier (e.g. CLG2-01) and annotated using a key to denote the elements outlined above. This key is provided in Appendix 2.

Each bibliography was then given a rating for the quality of the references from three possible ratings: 'Good', 'Average' and 'Poor'. For the purpose of this research, 'quality' was defined in parallel with the assessment criteria for the three selected CLG modules, in particular the requirement for students to select appropriate evidencebased, academic resources. A 'Good' rating meant that the bibliography included a range of mostly current and evidence-based academic sources. 'Average' bibliographies had some academic sources but also included examples of less rigorous literature. 'Poor' examples largely included non-evidence-based, outdated or otherwise unsuitable sources, perhaps with one or two more academic examples. The bibliographies were rated by three colleagues from beyond the core research team in 
order to reduce bias; an average of their ratings was taken to provide the final rating for each bibliography.

Final marks out of 100 were obtained for all 60 sample essays from the Health Sciences Student Assessment Office. These were compared against the bibliography rating.

\section{Results}

\section{Total number of references}

For CLG2 the total number of references used across the 20 essays was 327; these ranged from 9 to 30 references per essay with an average of 16.35 references per essay. For CLG4 the total number was 536; these ranged from 7 to 63 references per essay with an average of 26.8 references per essay. For CLG5 the total number was 608 ; these ranged from 18 to 51 references per essay with an average of 30.4 references per essay.

\section{Frequency of reference types}

In the essays for CLG2, the most common type of reference was journal articles (111 references), then websites (98), books (87) and reports (29). Two other reference types were noted and none were indeterminate. For CLG4 the most common type of reference was journal articles (261 references), then books (120), websites (114) and reports (40). There was 1 indeterminate reference and no other reference types. Finally, for CLG5 journal articles were the most frequent (221 references), then books (197), reports (131) and websites (58). There was 1 other reference type and no indeterminate references. Figure 1 compares the types of reference used across all three modules.

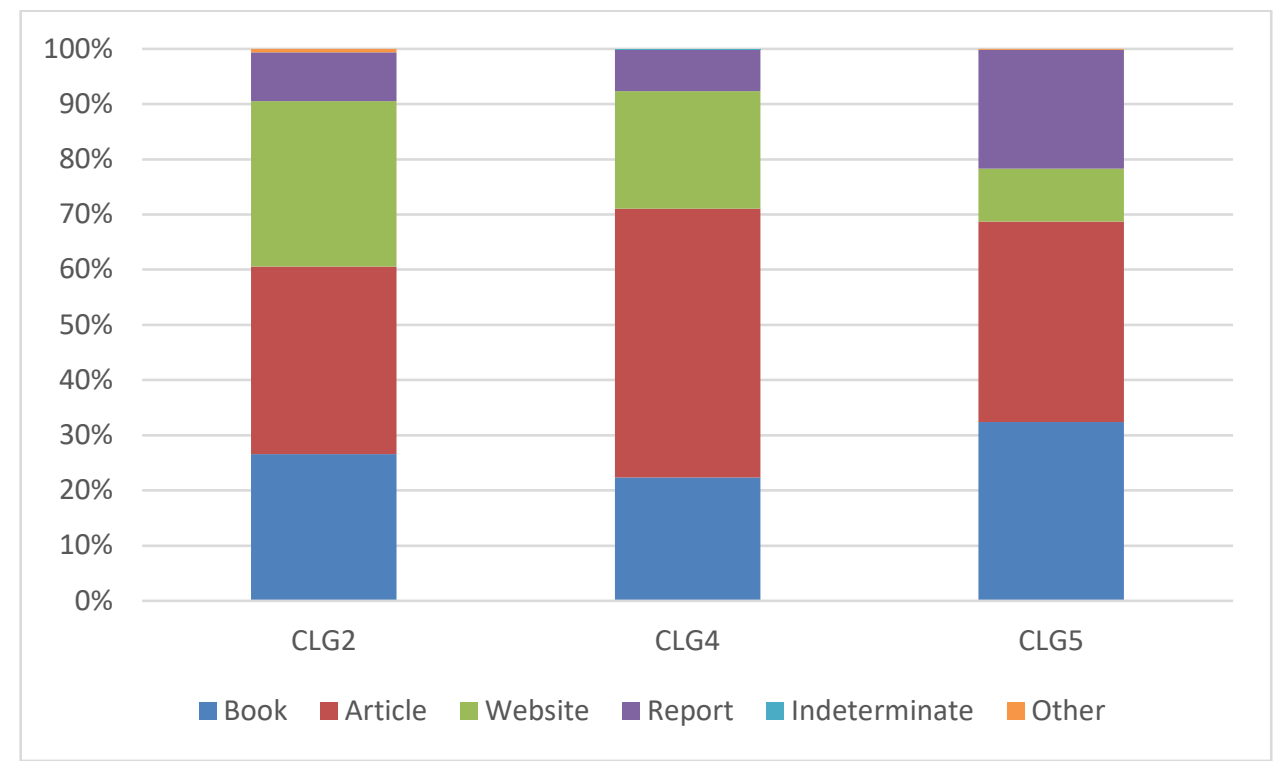

Figure 1. A Chart Showing the Types of References Used in CLGs 2, 4 and 5

\section{References from reading lists}

For CLG2, 274 references were not from the reading list, leaving 53 from the recommended module reading. CLG4 saw 516 references not from the reading list with an additional 20 coming from the recommended reading. Finally, CLG5 had 520 references not from the reading list and a further 88 from recommended items. 


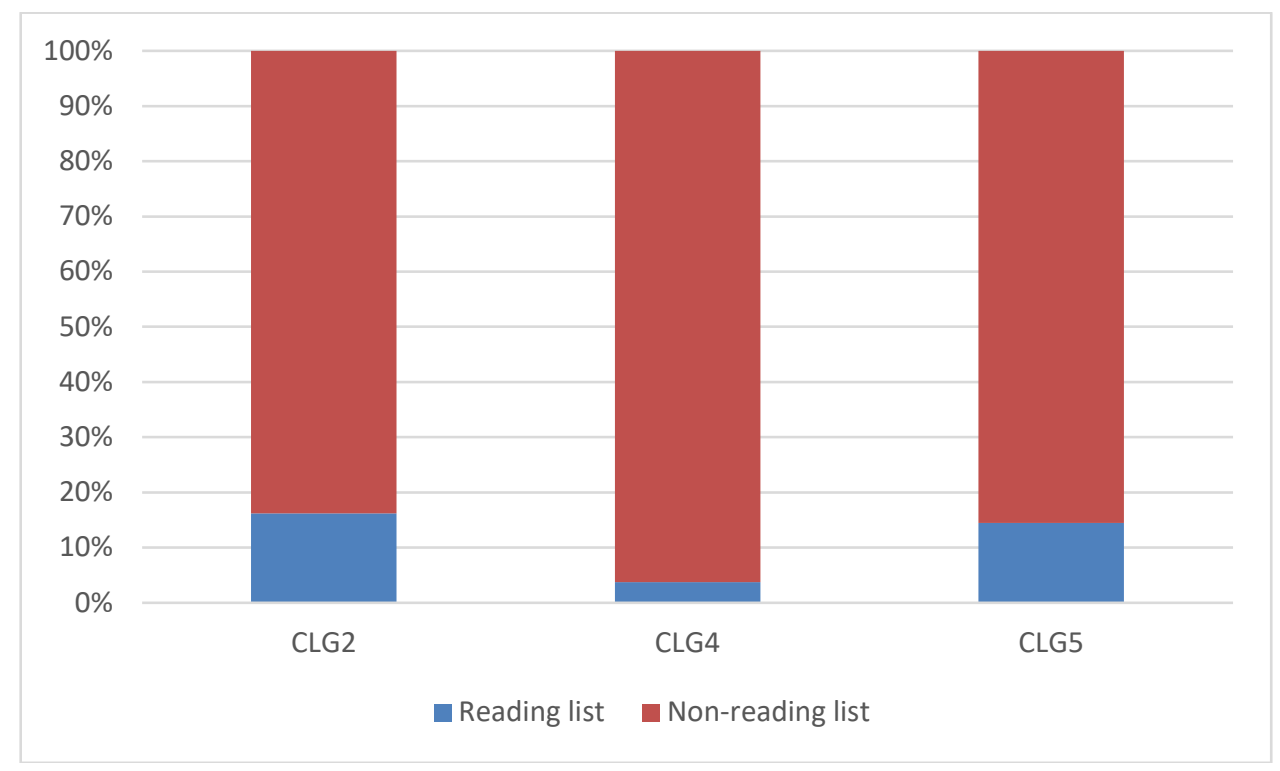

Figure 2. A Chart Showing the Proportion of Sources from a Reading List in CLGs 2, 4 and 5

\section{Bibliography ratings and final marks}

For CLG2, 4 bibliographies were rated 'Poor', 8 were 'Average' and 8 were 'Good'. The average mark (out of 100 in all cases) for all 20 essays was 55.4. The 'Poor' examples averaged a mark of 47.3, the 'Average' examples 52.9 and the 'Good' examples 62.

Of the CLG4 bibliographies, there were no 'Poor' examples, 11 were 'Average' and 9 were 'Good'; the essays scored 64 on average. The 'Average' examples had an average mark of 58.3 and the 'Good' examples 70.9.

Finally, for CLG5 there were again no 'Poor' examples, 9 'Average' and 11 'Good', with an average mark of 66.8. The 'Average' examples received a mark of 59.6 on average, and the 'Good' examples 72.7.

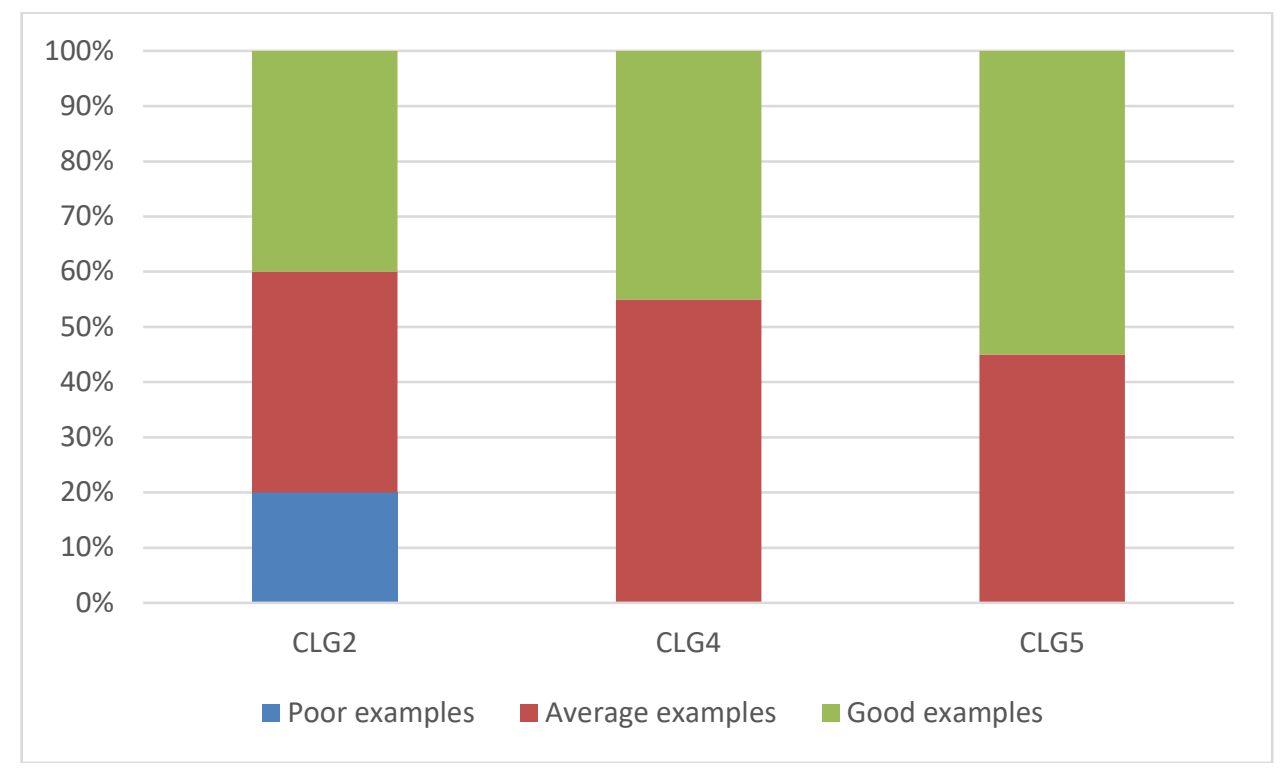

Figure 3. A Chart Showing the Proportion of Poor, Average and Good Bibliographies in CLGs 2, 4 and 5 


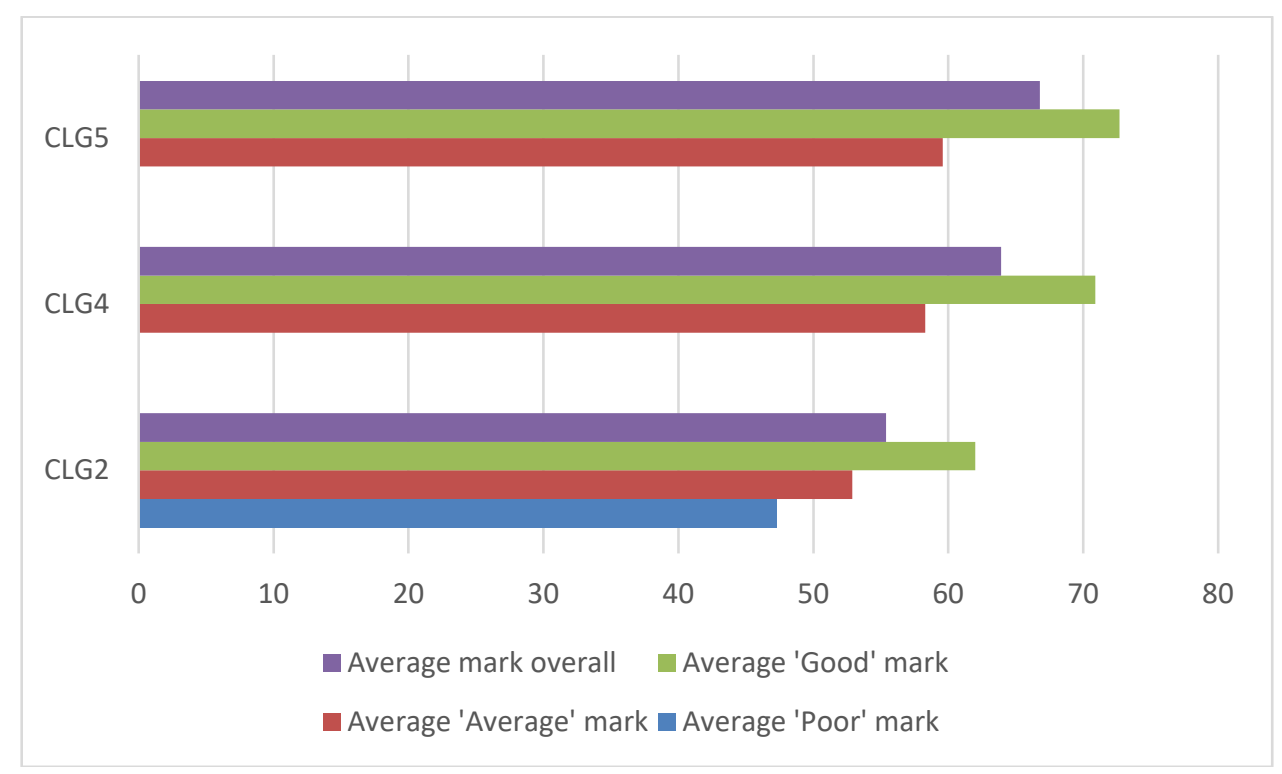

Figure 4. A Chart Comparing the Average Marks for Each Bibliography Rating and the Overall Average Mark for CLGs 2, 4 and 5

Results are provided in full in Appendix 3.

\section{Discussion}

\section{Range of resource types}

Across all three modules a range of different resource types was evident in the essays. Journal articles were the most common in all modules, with websites gradually becoming less heavily used. In general, it was encouraging that students had found and cited journal articles and that these were the most common reference type. However, it should be noted that, particularly in CLG2, many of these references were from professional journals (such as Nursing Times and Nursing Standard) and fewer from more overtly academic journals. Some students had therefore stuck very closely to one specific type of literature without broadening their reading into other areas. This may be due to the relative ease of access of such material, as well as their perceived relevance to the profession. Such a suggestion links to the findings in the literature that ease of access trumps quality of source as students' favoured selection criteria (e.g. Joo and Choi 2015, Kim and Sin 2011).

Numerous essays for CLG2 did not reference any journal articles at all, with students relying entirely on books and websites. This is perhaps not surprising given the introductory nature of the essay, although, notably, the assignment guidelines had asked students specifically to explore academic literature. These findings are broadly consistent with those in the literature (e.g. Gannon-Leary et al. 2006), although this study notes a higher use of journal articles as a source type. This might simply be a result of the strong focus within digital literacy teaching on using journal articles, although the literature noted that students are not always strongly influenced by such teaching sessions (Rosenblatt 2010: 56). An introduction to this topic is provided in year 1 of the BSc and foregrounded very strongly within a module in evidence-based practice in year 2, at which point academic staff place a much stronger emphasis on selecting appropriate, high quality sources. This could account for the increase in use of journal articles between CLGs 2 and 4, and suggests that at least some students 
improve their understanding of the link between evidence and argument as they progress through the programme.

\section{Quantity of references}

The number of references per essay rose notably from CLG2 to CLG4 and again to CLG5. This might indicate students growing in confidence and becoming more aware of different types of source material across the programme. The different essays also had a slightly different remit; the essay for CLG2 was much more reflective compared to the academic criticism required for CLGs 4 and 5. This likely meant that students needed additional references to back up their more complex arguments in the essays for later years.

\section{Source discovery}

In all modules there was clear evidence of students actively finding their own sources rather than relying on what had been provided via the respective module's reading list. For CLG2 around $84 \%$ of the references used were not from the reading list; this figure rose to around $96 \%$ for CLG4, although dropped back down to $86 \%$ for CLG5. This may be due to the more difficult subject matter, potentially meaning that students are less confident to explore the literature independently. It should be noted, however, that the CLG5 examples contained more references in total than the previous two essay submissions, so the number of references discovered independently remains significant. This generally upward trend is perhaps indicative of students becoming more confident with searching for resources at later stages. In year two (CLG4) students have also joined the degree pathway for their chosen field of practice, likely meaning that their choice of reading becomes more field-specific and is less likely to be recommended on a reading list.

\section{Quality of references}

Although it was encouraging to note that students were finding their own sources, the quality of those sources was often lacking. This was particularly true of the websites which students had cited; whilst some of these were relevant and focused (some students had referenced pages from the Nursing Times, for example), others were clearly not evidence-based. There was therefore mixed evidence of criticality from students; many seemed to have picked sources which, although mostly relevant, were not of suitable academic rigour or quality. In general this was more evident in CLG2 essays, although some students had still used poor quality references for CLG4. In general references for CLG5 were more academically focused, which might be expected from students in their final year of study. This broadly reflects the literature, which suggests that nursing students are able to find sources with relative ease, but demonstrate less ability to distinguish between high and low quality sources (Dee and Stanley 2005: 220). It was notable in some examples, particularly in 'Average' or 'Poor' bibliographies, that students appeared to have chosen sources simply because they matched the topic of the assignment, rather than because they provided the best quality evidence. These sources were often outdated or of questionable origin, suggesting a lack of evaluation and selection.

\section{Formatting of references}

Whilst many students had correctly formatted their references, there were numerous inconsistencies and errors. This made it very difficult in some cases to identify the type of reference being used, let alone to find it for further investigation. Although many of the errors were simple formatting problems (lack of italics, for example), some essays demonstrated systematic misunderstanding and misuse of the University's bespoke Harvard style (which students are asked to follow for all assignments). This was more generally observed in CLG2 essays, but was still evident across many of the CLG4 
examples. In CLG4 especially, students had incorrectly used abbreviations for journal titles, although references for CLG5 were largely formatted more successfully. It was not the primary purpose of this research to explore the formatting of references. However, the lack of attention to detail displayed by some students broadly agrees with findings in the literature, such as Rosenblatt's (2010: 57) assertion that students struggle to integrate source material into their work correctly. Whilst many students are therefore finding and selecting material of sufficient quality, they are not demonstrating the required skills to highlight those sources in their academic work.

\section{Presentation of bibliographies}

Many students had incorrectly presented their bibliographies, for example by using a numbered style or not presenting references in alphabetical order by author (the required convention in the department). Some had also separated their bibliographies into different reference types rather than in a single, combined list. Many students had also inconsistently referenced the same reference type in the same essay, making their bibliographies haphazard. This is perhaps indicative of students not spending ample time checking their references for consistency and accuracy before final submission. A well-presented bibliography will, of course, not in itself gain a student additional marks, and only a very limited proportion of each assignment's marks are awarded for accurate referencing. The marking criteria focus more overtly on the selection of relevant, cogent and well-integrated examples from the literature than the mechanics of referencing. It should also be noted that 'quality' in this research was more aligned to the academic rigour of the source material which students selected, rather than how they formatted their subsequent references. The overall quality of their bibliographies as determined by the research was therefore more weighted towards their critical selection of resources than reference formatting.

\section{Association between quality of bibliography and marks}

Across the three modules, the quality of bibliographies improved as students progressed through the programme. It was especially encouraging to see no 'Poor' bibliographies in years two or three, which one might expect as students improve their skills of referencing and source integration. This also demonstrated that, in general, students were showing an improved range of sources to be included in their reference lists.

For all three essay submissions there was a higher mark awarded to examples which demonstrated a higher quality bibliography, suggesting an ultimate association between quality of bibliography and mark received. This is demonstrated in Figure 4 in the Results section. Figure 4 shows that essays with 'Good' bibliographies received a higher mark than the overall average mark for that assignment; essays with 'Average' or 'Poor' bibliographies received a lower mark than the overall average mark. There were no examples of 'Poor' bibliographies for either CLG 4 or 5, suggesting that students' choice of references was improved in years 2 and 3 of the programme.

The average mark also improved year-on-year, indicating that students were gradually becoming more confident and capable in their writing. Although this is not necessarily surprising as students progress through the programme, it is encouraging to note that those students who engaged more successfully with source selection were ultimately rewarded with a higher mark. This provides an extremely attractive rationale for explaining to students the value of referencing and digital literacy, if only to highlight that mastering academic skills has a very tangible pay-off.

It would be easy to view these findings in a purely academic, rather than professional setting; after all, how often in practice do nurses have to format academic references 
and truly evidence their research base? However, the analytical and critical skills developed through referencing and digital literacy are surely crucial skills in practice as well. Sherriff, Wallis and Chaboyer (2007: 363) note that evidence-based practice has grown to become hugely important in nursing, and the vast majority of their research participants recognise the direct value of evidence to their practice. Without such skills, student nurses will therefore find it harder to respond to patients' needs and to grapple with the fast pace of information and research within the NHS.

\section{Conclusion}

Although some students evidenced appropriate use of high-quality, academic resources and were ultimately rewarded with a higher mark, many presented a mismatched list of low-quality, outdated or inappropriate sources which were inconsistently referenced. These students suitably engaged with journal articles, but had stuck too closely to professional literature rather than also engaging with more academically-focused research material.

The quality of sources which students chose to reference was often poor to average, showing little criticality or selection. Students seemed to have confused 'evidence' for any available source and had not suitably engaged with a more rigorous search process, despite indications of independent research. Furthermore, many students had incorrectly and/or inconsistently formatted both individual references and their bibliographies as a whole. In some cases it was difficult to identify the types of reference being used, or impossible to locate the cited item.

There was, though, a noteworthy improvement in quality as students progressed through the programme, both in terms of selection of resources and formatting of references. This suggests that efforts to address poor referencing practice should be focused to the early years of undergraduate programmes, at which point students are still honing their academic skills. Early intervention therefore ensures that all students are able to progress their skills and to observe the general trend of improvement seen in this study.

Academic skills are in many ways a precursor to students being able to survive and thrive in a clinical environment. By perfecting their skills of critical analysis and evidence-based practice in an academic context, students equip themselves with a breadth of knowledge and a skills base to apply with rigour and confidence in their professional lives. This is truly the interplay between theory and practice: the ability to demonstrate the application and advancement of skills and learning.

\section{Recommendations}

This study recommends:

- statistical analysis is carried out to test further the correlation between quality of bibliography and the mark awarded;

- academic programme and/or module teams consider learning outcomes and assessment guidelines with regard to use of source material, principally to make more explicit the range and types of resources students are expected to use in a given assignment; 
- $\quad$ students are provided with further guidance about the suitability of resources and how to reference them through face-to-face teaching and online support materials. This could be achieved initially through the digital literacy support provided by information professionals, but needs to be integrated more widely into the relevant programme with input from academic staff in order to have lasting impact for students;

- support in referencing and source selection is targeted to the first year of undergraduate programmes, where students will begin to form their approaches to academic writing and referencing and where this research has shown students to struggle;

- academics and information professionals make overt note, for students, of the association between good referencing practice and higher assignment marks;

- a clearer link is made for students between academic skills and professional working, to ensure that investment is made by student nurses in both theory and practice. 


\section{References}

Belenky, M.F. (1997) Women's Ways of Knowing: The Development of Self, Voice and Mind. $10^{\text {th }}$ Anniversary edn. New York: Basic Books

Brown, C.E., Kim, S.C., Stichler, J.F. and Fields, W. (2010) 'Predictors of Knowledge, Attitudes, Use and Future Use of Evidence-Based Practice Among Baccalaureate Nursing Students at Two Universities'. Nurse Education Today 30 (6), 521-527

Carlson, J. (2006) 'An Examination of Undergraduate Student Citation Behaviour'. Journal of Academic Librarianship 32 (1), 14-22

Davis, P.M. (2002) 'The Effect of the Web on Undergraduate Citation Behaviour: A 2000 Update'. College and Research Libraries 63 (1), 53-60

Davis, P.M. and Cohen, S.A. (2001) 'The Effect of the Web on Undergraduate Citation Behaviour: 1996-1999'. Journal of the American Society for Information Science and Technology 52, 309-314

Dee, C. and Stanley, E.E. (2005) 'Information-Seeking Behavior of Nursing Students and Clinical Nurses: Implications for Health Sciences Librarians'. Journal of the Medical Library Association 93 (2), 213-222

Eriksson, A.M. and Mäkitalo, A. (2013) 'Referencing as Practice: Learning to Write and Reason with Other People's Texts in Environmental Engineering Education'. Learning, Culture and Social Interaction 2 (3), 171-183

Gannon-Leary, P., Walton, G., Cader, R., Derbyshire, J. and Smith, A. (2006) 'Use of Evidence by Nursing Students: An Interdisciplinary Study'. Library \& Information Science Research 28 (2), 249-264

Georgas, H. (2015) 'Google vs. the Library (Part III): Assessing the Quality of Sources Found by Undergraduates'. Portal: Libraries and the Academy 15 (1), 133-161

Gimenez, J. (2008) 'Beyond the Academic Essay: Discipline-Specific Writing in Nursing and Midwifery'. Journal of English for Academic Purposes 7 (3), 151-164

Gray, K., Thompson, C., Clerehan, R., Sheard, J. and Hamilton, M. (2008) 'Web 2.0 Authorship: Issues of Referencing and Citation for Academic Integrity'. Internet and Higher Education 11 (2), 112-118

Heller-Ross, H. (2003) 'Assessing Outcomes with Nursing Research Assignments and Citation Analysis of Student Bibliographies'. The Reference Librarian 37 (77), 117-136

Joo, S. and Choi, N. (2015) 'Factors Affecting Undergraduates' Selection of Online Library Resources in Academic Tasks: Usefulness, Ease-of-use, Resource Quality, and Individual Differences'. Library Hi Tech 33 (2), 272-291

Kim, K. and Sin, S.J. (2011) 'Selecting Quality Sources: Bridging the Gap Between the Perception and Use of Information Sources'. Journal of Information Science 37 (2), 178-188

King, P. and Kitchener, K.S. (1994) Developing Reflective Judgement: Understanding and Promoting Intellectual Growth and Critical Thinking in Adolescents and Adults. San Francisco: Jossey-Bass Publishers

Kohn, K.C. and Gordon, L. (2014) 'Citation Analysis as a Tool for Collection Development and Instruction'. Collection Management 39 (4), 275-296 
Middleton, A. (2005) 'An Attempt to Quantify the Quality of Student Bibliographies'. Performance Management and Metrics 6 (1), 7-18

Mill, D.H. (2008) 'Undergraduate Information Resource Choices'. College and Research Libraries 69 (4), 342-355

Nayda, R. and Rankin, E. (2008) 'Information Literacy Skill Development and Lifelong Learning: Exploring Nursing Students' and Academics' Understandings'. Australian Journal of Advanced Nursing 26 (2), 27-33

Nursing and Midwifery Council (2015) The Code for Nurses and Midwives. [online] available from <https://www.nmc.org.uk/globalassets/sitedocuments/nmc-publications/nmccode.pdf> [11 September 2018]

Pitt, V., Powis, D., Levett-Jones, T. and Hunter, S. (2015) 'The Influence of Critical Thinking Skills on Performance and Progression in a Pre-Registration Nursing Program'. Nurse Education Today 35 (1), 125-131

Profetto-McGrath, J. (2003) 'The Relationship of Critical Thinking Skills and Critical Thinking Dispositions of Baccalaureate Nursing Students'. Journal of Advanced Nursing 43 (6), 569-577

Rosenblatt, S. (2010) 'They Can Find It, But They Don't Know What to Do with It: Describing the Use of Scholarly Literature by Undergraduate Students'. Journal of Information Literacy 4 (2), 50-61

Sherriff, K.L., Wallis, M. and Chaboyer, W. (2007). 'Nurses' Attitudes to and Perceptions of Knowledge and Skills Regarding Evidence-Based Practice'. International Journal of Nursing Practice 13 (6), 363-369

Sullivan, E.A. (2012) 'Critical Thinking in Clinical Nurse Education: Application of Paul's Model of Critical Thinking'. Nurse Education in Practice 12 (6), 322-327

Ursin, L., Lindsay, E.B. and Johnson, C.M. (2004) 'Assessing Library Instruction in the Freshman Seminar: A Citation Analysis Study'. Reference Services Review 32 (3), 284-292

Zuriguel-Pérez, E., Lluch-Canut, M.T., Falcó-Pegueroles, A., Puig-Llobet, M., Arroyo, C.M. and Roldán-Merino, J. (2014) 'Critical Thinking in Nursing: Scoping Review of the Literature'. International Journal of Nursing Practice 21 (6), 820-830 


\section{Appendix 1. Assignment Guidelines for CLGs 2, 4 and 5}

\section{CLG2}

You are required to write an essay entitled: What makes me a good nurse?

Your essay should consider the attributes, values and behaviours that good nurses demonstrate. Choose ONE attribute, value or behaviour of a good nurse that you feel is relevant to you. Discuss how you have demonstrated your chosen attribute, value or behaviour in your own practice, with reference to the learning undertaken during this module.

The following aspects should be included

- A brief overview of the range of attributes, values and behaviours of a good nurse, presented within the personal, professional, political, and social context.

- The attribute, value or behaviour under exploration should be clearly stated and the rationale for your choice provided.

- Differing perspectives of the attribute, value or behaviour, including those of patients/clients should be considered.

- A comparison between the attribute, value or behaviour and your personal abilities should be given.

- You should refer to observations from practice and relevant nursing literature to develop your discussion.

- How the attribute, value or behaviour was applied to your clinical practice.

- The development of aesthetic knowledge and individual professional identity should be considered.

- What you have learned through reading, practice and discussion in this essay; areas for future development should be clearly identified.

You must use predominantly nursing literature to support your work.

You may draw on experiences from your learning log and portfolio within your discussion.

\section{CLG4}

You are required to write an essay which reflects on a clinical incident and explores the way in which nurses and healthcare professionals discuss or interact with patients/clients.

Your essay should:

- Consider how specific aspects (e.g. the language, terminology or descriptions used) of this discussion represents the values, attitudes, beliefs and behaviours of the nurse and what influence this has regarding the relationship between the nurse and the patient/client

Your essay must include:

- Critical reflection on the implications of this incident for nursing practice.

- Reference to the academic literature from the health and social care related disciplines.

- Discussion of how this learning will influence your future nursing practice.

- An example from your observed discussion in the essay appendix. 


\section{CLG5}

You are required to write an essay which identifies and discusses an ethical decision or action that has arisen in practice.

The ethical decision or action you choose as the focus of your essay might be one you have made, one you have observed, or one that you are interested in that has recently been reported in the media. The ethical decision or action might have initially raised feelings of discomfort and could have resulted in either a good or bad outcome. The exact focus of the essay should be negotiated with your Co-operative Learning Group (CLG) Facilitator.

Aligned to the learning outcomes for this module, this essay should aim to answer the following questions:

1. Drawing on pertinent reading, what are the underlying ethical and legal issues and principles involved in the ethical decision or action to arise in practice?

2. What possible courses of action would be available for the health professionals involved?

3. What for and against arguments are there to support or reject those options?

4. In order to draw conclusions and make an ethically sound decision, what ought to be done and why (perhaps 'on balance' of all the above)? 
Appendix 2. Key Used for Citation Analysis Exercise

\begin{tabular}{|l|l|l|}
\hline$n=$ no. of references & $B=$ book or chapter & $R=$ report \\
\hline$L=$ on list & $A=$ journal article & $O=$ other \\
\hline $\mathrm{NL}=$ not on list & W = website & $\mathrm{I}=$ indeterminate \\
\hline
\end{tabular}


Appendix 3. Results in Full

\section{Citation analysis}

Table 1. Citation Analysis Results for CLG2

\begin{tabular}{|c|c|c|c|c|c|c|c|c|c|}
\hline Code & $\mathbf{n}$ & B & A & W & $\mathbf{R}$ & I & 0 & $\mathbf{L}$ & NL \\
\hline CLG2-01 & 19 & 5 & 3 & 10 & 1 & 0 & 0 & 4 & 15 \\
\hline CLG2-02 & 17 & 6 & 0 & 10 & 1 & 0 & 0 & 1 & 16 \\
\hline CLG2-03 & 21 & 3 & 7 & 7 & 4 & 0 & 0 & 7 & 14 \\
\hline CLG2-04 & 18 & 1 & 6 & 8 & 3 & 0 & 0 & 2 & 16 \\
\hline CLG2-05 & 24 & 3 & 11 & 8 & 2 & 0 & 0 & 1 & 23 \\
\hline CLG2-06 & 10 & 5 & 3 & 1 & 1 & 0 & 0 & 0 & 10 \\
\hline CLG2-07 & 12 & 0 & 3 & 8 & 1 & 0 & 0 & 3 & 9 \\
\hline CLG2-08 & 17 & 12 & 3 & 2 & 0 & 0 & 0 & 3 & 14 \\
\hline CLG2-09 & 14 & 2 & 9 & 2 & 1 & 0 & 0 & 4 & 10 \\
\hline CLG2-10 & 25 & 4 & 11 & 7 & 3 & 0 & 0 & 0 & 25 \\
\hline CLG2-11 & 16 & 12 & 0 & 3 & 1 & 0 & 0 & 9 & 7 \\
\hline CLG2-12 & 10 & 8 & 0 & 1 & 1 & 0 & 0 & 3 & 7 \\
\hline CLG2-13 & 30 & 5 & 21 & 2 & 2 & 0 & 0 & 2 & 28 \\
\hline CLG2-14 & 21 & 4 & 7 & 7 & 3 & 0 & 0 & 3 & 18 \\
\hline CLG2-15 & 10 & 4 & 3 & 3 & 0 & 0 & 0 & 1 & 9 \\
\hline CLG2-16 & 12 & 5 & 5 & 2 & 0 & 0 & 0 & 2 & 10 \\
\hline CLG2-17 & 14 & 3 & 8 & 0 & 1 & 0 & 2 & 1 & 13 \\
\hline CLG2-18 & 16 & 1 & 5 & 10 & 0 & 0 & 0 & 0 & 16 \\
\hline CLG2-19 & 9 & 1 & 0 & 6 & 2 & 0 & 0 & 3 & 6 \\
\hline CLG2-20 & 12 & 3 & 6 & 1 & 2 & 0 & 0 & 4 & 8 \\
\hline Total & 327 & 87 & 111 & 98 & 29 & 0 & 2 & 53 & 274 \\
\hline Average & 16.35 & 4.35 & 5.55 & 4.9 & 1.45 & 0 & 0.1 & 2.65 & 13.7 \\
\hline Min & 9 & 0 & 0 & 0 & 0 & 0 & 0 & 0 & 6 \\
\hline Max & 30 & 12 & 21 & 10 & 4 & 0 & 2 & 9 & 28 \\
\hline
\end{tabular}

Table 2. Citation Analysis Results for CLG4

\begin{tabular}{|l|r|r|r|r|r|r|r|r|r|}
\hline Code & \multicolumn{1}{|l|}{$\mathbf{n}$} & \multicolumn{1}{l|}{ B } & \multicolumn{1}{|c|}{ A } & \multicolumn{1}{l|}{ W } & \multicolumn{1}{l|}{ R } & \multicolumn{1}{l|}{ I } & \multicolumn{1}{l|}{ O } & \multicolumn{1}{l|}{ L } & NL \\
\hline CLG4-01 & 27 & 2 & 7 & 16 & 2 & 0 & 0 & 1 & 26 \\
\hline CLG4-02 & 42 & 11 & 19 & 10 & 2 & 0 & 0 & 0 & 42 \\
\hline CLG4-03 & 26 & 10 & 11 & 2 & 3 & 0 & 0 & 4 & 22 \\
\hline CLG4-04 & 25 & 4 & 19 & 1 & 1 & 0 & 0 & 2 & 24 \\
\hline CLG4-05 & 14 & 0 & 13 & 0 & 1 & 0 & 0 & 0 & 14 \\
\hline CLG4-06 & 25 & 6 & 12 & 4 & 3 & 0 & 0 & 2 & 23 \\
\hline
\end{tabular}




\begin{tabular}{|l|r|r|r|r|r|r|r|r|r|}
\hline CLG4-07 & 20 & 9 & 6 & 2 & 3 & 0 & 0 & 1 & 19 \\
\hline CLG4-08 & 35 & 7 & 22 & 2 & 4 & 0 & 0 & 0 & 35 \\
\hline CLG4-09 & 33 & 4 & 14 & 12 & 3 & 0 & 0 & 0 & 33 \\
\hline CLG4-10 & 7 & 0 & 4 & 3 & 0 & 0 & 0 & 0 & 7 \\
\hline CLG4-11 & 63 & 9 & 39 & 13 & 2 & 0 & 0 & 1 & 62 \\
\hline CLG4-12 & 27 & 11 & 3 & 11 & 2 & 0 & 0 & 2 & 25 \\
\hline CLG4-13 & 19 & 4 & 11 & 4 & 0 & 0 & 0 & 0 & 19 \\
\hline CLG4-14 & 29 & 5 & 18 & 4 & 2 & 0 & 0 & 1 & 28 \\
\hline CLG4-15 & 42 & 4 & 28 & 8 & 2 & 0 & 0 & 0 & 42 \\
\hline CLG4-16 & 25 & 6 & 11 & 5 & 2 & 1 & 0 & 0 & 25 \\
\hline CLG4-17 & 19 & 6 & 9 & 2 & 2 & 0 & 0 & 3 & 16 \\
\hline CLG4-18 & 24 & 11 & 4 & 7 & 2 & 0 & 0 & 0 & 24 \\
\hline CLG4-19 & 19 & 7 & 7 & 3 & 2 & 0 & 0 & 3 & 16 \\
\hline CLG4-20 & 15 & 4 & 4 & 5 & 2 & 0 & 0 & 0 & 15 \\
\hline Total & $\mathbf{5 3 6}$ & $\mathbf{1 2 0}$ & $\mathbf{2 6 1}$ & $\mathbf{1 1 4}$ & $\mathbf{4 0}$ & $\mathbf{1}$ & $\mathbf{0}$ & $\mathbf{2 0}$ & $\mathbf{5 1 7}$ \\
\hline Average & $\mathbf{2 6 . 8}$ & $\mathbf{6}$ & $\mathbf{1 3 . 0 5}$ & $\mathbf{5 . 7}$ & $\mathbf{2}$ & $\mathbf{0 . 0 5}$ & $\mathbf{0}$ & $\mathbf{1}$ & $\mathbf{2 5 . 8 5}$ \\
\hline Min & 7 & 0 & 3 & 0 & 0 & 0 & 0 & 0 & 7 \\
\hline Max & 63 & 11 & 39 & 16 & 4 & 1 & 0 & 4 & 62 \\
\hline
\end{tabular}

Table 3. Citation Analysis Results for CLG5

\begin{tabular}{|c|c|c|c|c|c|c|c|c|c|}
\hline Code & $\mathbf{n}$ & B & $A$ & $\mathbf{W}$ & $\mathbf{R}$ & I & 0 & $\mathbf{L}$ & $\mathrm{NL}$ \\
\hline CLG5-01 & 21 & 2 & 11 & 0 & 8 & 0 & 0 & 4 & 17 \\
\hline CLG5-02 & 29 & 14 & 2 & 7 & 6 & 0 & 0 & 5 & 24 \\
\hline CLG5-03 & 29 & 9 & 16 & 0 & 4 & 0 & 0 & 3 & 26 \\
\hline CLG5-04 & 33 & 8 & 6 & 10 & 9 & 0 & 0 & 8 & 25 \\
\hline CLG5-05 & 24 & 9 & 9 & 2 & 4 & 0 & 0 & 4 & 20 \\
\hline CLG5-06 & 30 & 10 & 15 & 0 & 4 & 0 & 1 & 4 & 26 \\
\hline CLG5-07 & 43 & 13 & 22 & 1 & 7 & 0 & 0 & 4 & 39 \\
\hline CLG5-08 & 29 & 9 & 11 & 1 & 8 & 0 & 0 & 5 & 24 \\
\hline CLG5-09 & 25 & 5 & 9 & 2 & 9 & 0 & 0 & 4 & 21 \\
\hline CLG5-10 & 35 & 14 & 13 & 1 & 7 & 0 & 0 & 5 & 30 \\
\hline CLG5-11 & 35 & 11 & 10 & 3 & 11 & 0 & 0 & 4 & 31 \\
\hline CLG5-12 & 22 & 2 & 12 & 4 & 4 & 0 & 0 & 3 & 19 \\
\hline CLG5-13 & 22 & 6 & 5 & 3 & 8 & 0 & 0 & 1 & 21 \\
\hline CLG5-14 & 34 & 16 & 12 & 1 & 5 & 0 & 0 & 4 & 30 \\
\hline CLG5-15 & 42 & 20 & 9 & 3 & 10 & 0 & 0 & 7 & 35 \\
\hline CLG5-16 & 18 & 8 & 3 & 1 & 6 & 0 & 0 & 3 & 15 \\
\hline CLG5-17 & 25 & 3 & 17 & 1 & 4 & 0 & 0 & 4 & 21 \\
\hline CLG5-18 & 51 & 16 & 13 & 11 & 11 & 0 & 0 & 6 & 45 \\
\hline
\end{tabular}




\begin{tabular}{|l|r|r|r|r|r|r|r|r|r|}
\hline CLG5-19 & 23 & 8 & 6 & 7 & 2 & 0 & 0 & 4 & 19 \\
\hline CLG5-20 & 38 & 14 & 20 & 0 & 4 & 0 & 0 & 6 & 32 \\
\hline Total & $\mathbf{6 0 8}$ & $\mathbf{1 9 7}$ & $\mathbf{2 2 1}$ & $\mathbf{5 8}$ & $\mathbf{1 3 1}$ & $\mathbf{0}$ & $\mathbf{1}$ & $\mathbf{8 8}$ & $\mathbf{5 2 0}$ \\
\hline Average & $\mathbf{3 0 . 4}$ & $\mathbf{9 . 8 5}$ & $\mathbf{1 1 . 0 5}$ & $\mathbf{2 . 9}$ & $\mathbf{6 . 5 5}$ & $\mathbf{0}$ & $\mathbf{0 . 0 5}$ & $\mathbf{4 . 4}$ & $\mathbf{2 6}$ \\
\hline Min & 18 & 2 & 2 & 0 & 2 & 0 & 0 & 1 & 15 \\
\hline Max & 51 & 20 & 22 & 11 & 11 & 0 & 1 & 8 & 45 \\
\hline
\end{tabular}

\section{Bibliography ratings}

Table 4. Bibliography Ratings for All Three CLG Modules

\begin{tabular}{|c|c|c|c|c|c|c|c|c|}
\hline \multicolumn{3}{|c|}{ CLG2 } & \multicolumn{3}{|c|}{ CLG4 } & \multicolumn{3}{|c|}{ CLG5 } \\
\hline Code & Rating & Mark & Code & Rating & Mark & Code & Rating & Mark \\
\hline CLG2-01 & Average & 61 & CLG4-01 & Average & 62 & CLG5-01 & Good & 65 \\
\hline CLG2-02 & Poor & 36 & CLG4-02 & Average & 90 & CLG5-02 & Average & 72 \\
\hline CLG2-03 & Good & 54 & CLG4-03 & Good & 90 & CLG5-03 & Good & 80 \\
\hline CLG2-04 & Average & 62 & CLG4-04 & Good & 70 & CLG5-04 & Average & 50 \\
\hline CLG2-05 & Good & 72 & CLG4-05 & Average & 70 & CLG5-05 & Average & 43 \\
\hline CLG2-06 & Average & 51 & CLG4-06 & Good & 58 & CLG5-06 & Good & 66 \\
\hline CLG2-07 & Average & 50 & CLG4-07 & Good & 69 & CLG5-07 & Average & 47 \\
\hline CLG2-08 & Average & 64 & CLG4-08 & Good & 78 & CLG5-08 & Average & 75 \\
\hline CLG2-09 & Good & 63 & CLG4-09 & Average & 48 & CLG5-09 & Good & 68 \\
\hline CLG2-10 & Good & 75 & CLG4-10 & Average & 20 & CLG5-10 & Good & 80 \\
\hline CLG2-11 & Poor & 57 & CLG4-11 & Good & 87 & CLG5-11 & Good & 76 \\
\hline CLG2-12 & Poor & 46 & CLG4-12 & Average & 42 & CLG5-12 & Good & 60 \\
\hline CLG2-13 & Good & 58 & CLG4-13 & Average & 82 & CLG5-13 & Good & 82 \\
\hline CLG2-14 & Average & 65 & CLG4-14 & Average & 53 & CLG5-14 & Average & 79 \\
\hline CLG2-15 & Good & 45 & CLG4-15 & Good & 73 & CLG5-15 & Average & 72 \\
\hline CLG2-16 & Good & 45 & CLG4-16 & Average & 68 & CLG5-16 & Average & 46 \\
\hline CLG2-17 & Good & 84 & CLG4-17 & Good & 73 & CLG5-17 & Good & 90 \\
\hline CLG2-18 & Average & 50 & CLG4-18 & Average & 59 & CLG5-18 & Good & 75 \\
\hline CLG2-19 & Poor & 50 & CLG4-19 & Good & 40 & CLG5-19 & Average & 52 \\
\hline CLG2-20 & Average & 20 & CLG4-20 & Average & 47 & CLG5-20 & Good & 58 \\
\hline & $\begin{array}{l}\text { Total } \\
\text { poor }\end{array}$ & 4 & & $\begin{array}{l}\text { Total } \\
\text { poor }\end{array}$ & 0 & & $\begin{array}{l}\text { Total } \\
\text { poor }\end{array}$ & 0 \\
\hline & \begin{tabular}{|l} 
Total \\
average
\end{tabular} & 8 & & \begin{tabular}{|l} 
Total \\
average
\end{tabular} & 11 & & \begin{tabular}{|l} 
Total \\
average
\end{tabular} & 9 \\
\hline & $\begin{array}{l}\text { Total } \\
\text { good }\end{array}$ & 8 & & $\begin{array}{l}\text { Total } \\
\text { good }\end{array}$ & 9 & & $\begin{array}{l}\text { Total } \\
\text { good }\end{array}$ & 11 \\
\hline & $\begin{array}{l}\text { Average } \\
\text { mark }\end{array}$ & 55.4 & & $\begin{array}{l}\text { Average } \\
\text { mark }\end{array}$ & 63.9 & & $\begin{array}{l}\text { Average } \\
\text { mark }\end{array}$ & 66.8 \\
\hline
\end{tabular}




\begin{tabular}{|l|l|l|l|l|r|r|l|r|}
\hline & $\begin{array}{l}\text { Average } \\
\text { 'Poor' }\end{array}$ & 47.3 & & $\begin{array}{l}\text { Average } \\
\text { 'Poor' }\end{array}$ & N/A & & $\begin{array}{l}\text { Average } \\
\text { 'Poor' }\end{array}$ & N/A \\
\hline & $\begin{array}{l}\text { Average } \\
\text { 'Average' }\end{array}$ & 52.9 & & $\begin{array}{l}\text { Average } \\
\text { 'Average' }\end{array}$ & 58.3 & & $\begin{array}{l}\text { Average } \\
\text { 'Average' }\end{array}$ & 59.6 \\
\hline & $\begin{array}{l}\text { Average } \\
\text { 'Good' }\end{array}$ & 62 & & $\begin{array}{l}\text { Average } \\
\text { 'Good' }\end{array}$ & 70.9 & & $\begin{array}{l}\text { Average } \\
\text { 'Good' }\end{array}$ & 72.7 \\
\hline
\end{tabular}

